\title{
APPLYING DYNAMIC EVALUATION APPROACH IN EDUCATION ${ }^{1}$
}

\author{
Vasilios Grammatikopoulos, Athanasios Koustelios, \\ Nikolaos Tsigilis, and Yannis Theodorakis
}

University of Thessaly, Department of Physical Education

and Sports Science, Trikala, Greece

\begin{abstract}
The purpose of the current study was to implement a newly proposed evaluation method (Dimitropoulos, 1999), that is, the dynamic evaluation approach in the field of education. The dynamic approach was applied in order to evaluate the Olympic Education Program in Greece. The results of the present field study were encouraging. Dynamic evaluation appeared to be a promising tool concerning the evaluation of the educational program. It was, however, considered premature to draw firm conclusions as dynamic evaluation does not depend on any of the well-known evaluation models. Therefore, it is proposed that the method should be further tested in the future to ensure its evaluation efficiency.
\end{abstract}

The conduct of evaluation in the educational field has been a subject of interest for many years. As a result, many alternative evaluation models have been developed. The dynamic evaluation method proposed by Dimitropoulos (1999) is not based on any of the known evaluation models, since its structure is characterized by an attempted synthesis of several methods, depending on occasion. In detail, the structure of the above model is based on "selectivity" (Cronbach, 1982; Worthen \& Sanders, 1987) and "dynamism".

Given the many alternative models provided, an evaluator has two choices: either to adopt a specific evaluation model and run the procedure, or to select from the different models those elements that are most appropriate for the specific occasion. The second choice refers to the condition of "selectivity" that is present in every step of the dynamic 
evaluation method. Therefore, "selectivity" is characterized by the combination of different methods and approaches (e.g., internal-external evaluation, summative-formative evaluation, qualitative-quantitative methods).

"Dynamism", the second basic component of the dynamic evaluation procedure, is borrowed from a "systems approach" (Pekelis, 1986). A procedure could be called a "system" when it consists of three basic functional units (a) input, (b) process, and (c) output and its function is determined by interdependence, interaction, self-control and selfcorrection of its basic parts (Pekelis, 1986). Self-control and self-correction are the salient features of dynamic evaluation. Self-control of the units is ensured with (d) additional monitoring, whereas (e) feedback meets the condition of self-correction as a fifth essential function (Dimitropoulos, 1999). Thus, dynamic evaluation is the control mechanism of an evaluating procedure. It controls the procedure and provides feedback continuously.

In conclusion, an evaluation is dynamic when it is: (a) continuous, (b) part of the procedure, (c) flexible, (d) self-controlled and self-corrected. Dynamic evaluation operates like a "system" and it is characterized by "selectivity". Furthermore, dynamic evaluation constitutes an integral part of the evaluating process and is not simply applied in parallel with it. The significance of dynamic evaluation is that it aspires to secure the success of the evaluating process during its implementation.

\section{SCHOOL SETTING}

INPUT UNIT $\quad$ PROCESS UNIT OUTPUT UNIT

Training

Designing

Implementation Outcomes

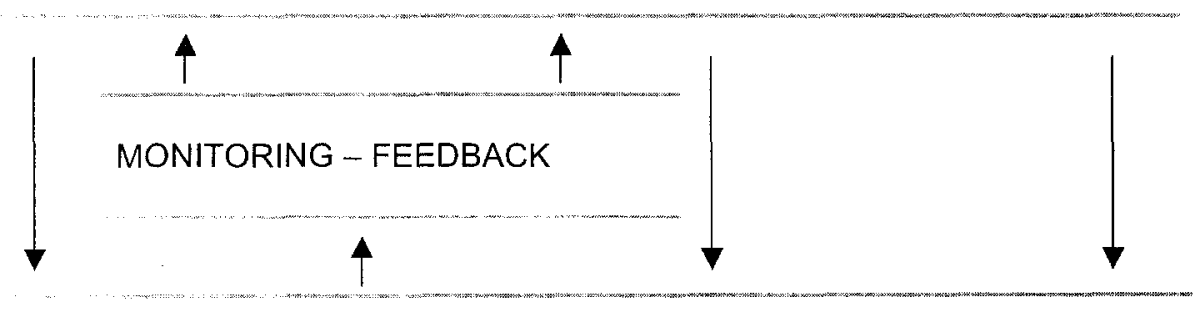

DYNAMIC EVALUATION

Figure 1: A "System" for Dynamic Evaluation of an Educational Program (Adjusted from Dimitropoulos, 1999)

The advantage of dynamic evaluation is that it does not exclude any of the evaluation models, but occasionally exploits the elements of which they consist. On the 
other hand, a dynamic approach is not based on any of the well-known evaluation models. Furthermore, since it has not yet been applied, experimental data cannot be provided.

The aim of the current study was to evaluate the Olympic Education Program (OEP) through a dynamic approach, in order to provide evidence for the suitability and appropriateness of dynamic evaluation in education.

The Olympic Education Program (OEP) has been implemented in the Greek education system since 2001 in order to serve the following purposes for the students of all school levels: (a) learn the history of modern and ancient Olympic Games; (b) ensure the principles and values of sports (e.g., fair play, respect for rules, respect for co-athletes); (c) understand the importance of the Olympic Games; (d) realize the essential role of volunteerism for the success of the Games; (e) develop skills related with behavioral control during sport and life in general, and ( $f$ ) learn about the importance of exercise to health (Kioumourtzoglou, et al., 2001).

Certainly, Olympic education is not a novel idea. Several approaches to Olympic education in school curricula evolved through the efforts of cities or nations that hosted Olympic games (e.g., Los Angeles -1984, Calgary - 1988, Lillehammer - 1994, Olympic day and Olympic Week packages by the United States Olympic Committee and the German National Olympic Committee; Binder, 2001). However, these efforts lacked theoretical unity and subsequent evaluation (Naul, 1998), as "they seemed to resonate with teachers as a source for integrated and imaginative pedagogical ideas and activities" (Binder, 1994).

Dynamic evaluation was adopted to evaluate the OEP, with its process being a part of the program implementation. Educators, external evaluators and the program administrators were informed about the evaluation procedures prior training.

\section{Method}

The evaluation of the OEP started in 2001, aiming at: (a) the initial design and training ol' the program; (b) program implementation; (c) the extent to which the purposes of the program were achieved, and (d) examining students' reception of the program.

Initially, the design of the program was evaluated by the Education Administration of the Organizing Committee for the Olympic Games "Athens 2004". Several professors from the field of physical education and education in general had the authority to supervise and execute the evaluation of the program design through certain evaluation procedures included in Kioumourtzoglou et al. (2001).

The evaluation personnel developed a number of instruments for evaluation purposes. First, the Professional Development Evaluation Form (PDEF) instrument was developed to evaluate the training program itself (Grammatikopoulos, Papacharisis, Koustelios, Tsigilis, \& Theodorakis, 2004). The PDEF instrument consisted of three factors containing 21 items. Exploratory factor analysis indicated a three-factor solution with high internal consistency. The three factors obtained were training, study groups, and total impression. Results indicated that the instrument had adequate psychometric properties (Grammatikopoulos, Papacharisis, et al., 2004).

A second instrument was developed to evaluate the implementation of the educational program (Grammatikopoulos, Tsigilis, Koustelios \& Theodorakis, in press). The Evaluation Scale of Educational Program's Implementation (ESEPI) instrument 
consisted of six factors containing 26 items. Exploratory factor analysis indicated a sixfactor solution with high internal consistency. The six factors obtained were facilities, administration, educational material, relationships, educational procedure, and training.

In terms of educational training evaluation, the study took into account that it should be carried out immediately after or during the program implementation, because only then it could be possible to judge the effectiveness of training (Guskey, 2000). Consequently, physical educators carried out an internal evaluation of OEP training twice: first, immediately after the end of the procedure and second, after the end of the school year (summative evaluation) (Grammatikopoulos, Tsigilis, et al., in press).

\section{OEP dynamic evaluation}

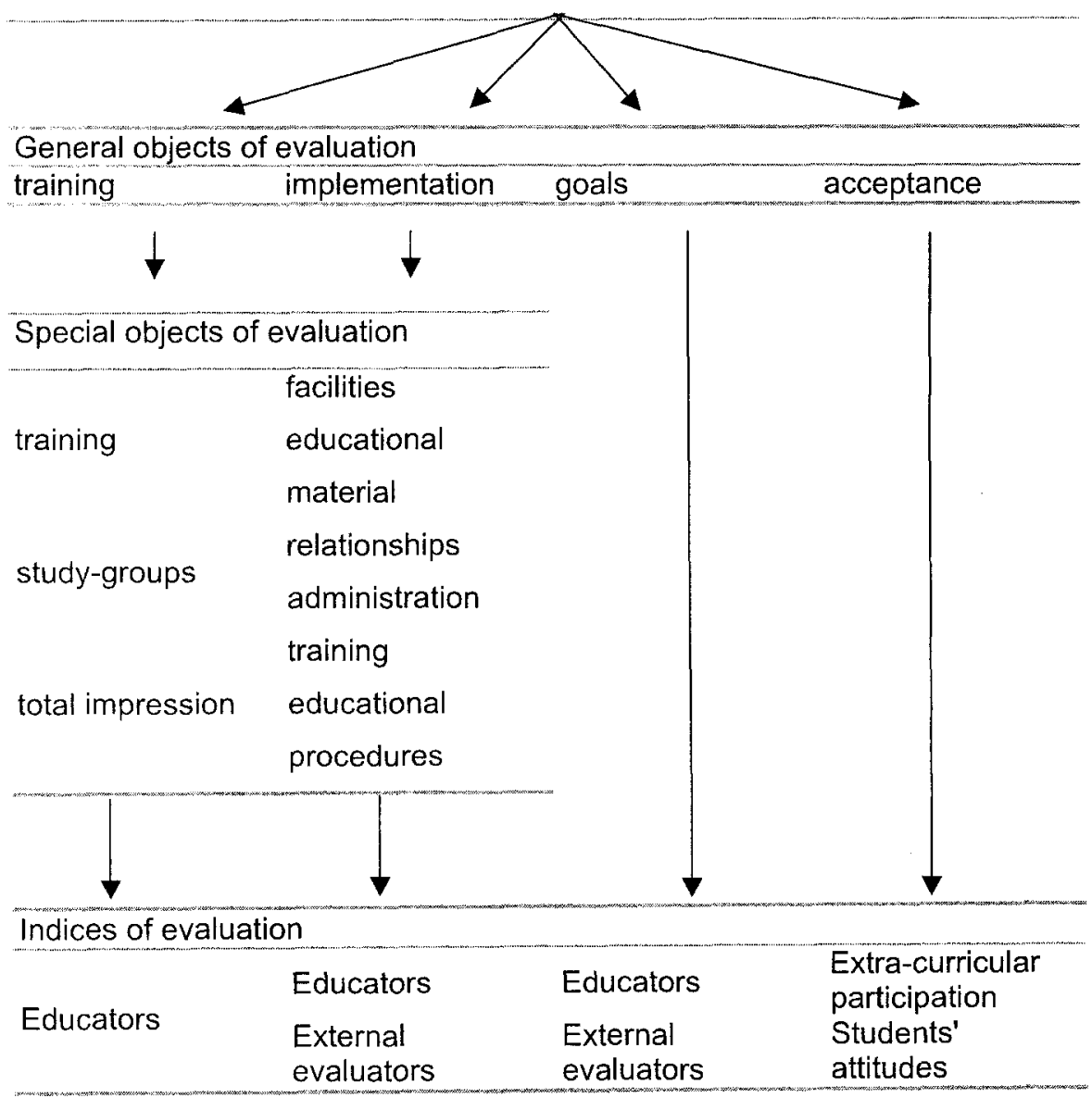

Figure 2: Design of the Dynamic Evaluation Procedure of the OEP 


\section{Results}

The implementation of the OEP and the extent to which the goals were achieved were evaluated after the end of the school year (Grammatikopoulos, 2004; Grammatikopoulos, Tsigilis, et al., in press). Internal and external evaluation procedures were adopted in order to meet the condition of self-control. Physical educators and external evaluators participated for the combination of the internal and external evaluation procedures (Grammatikopoulos, 2004) to enhance evaluation credibility and validity (Nevo, 2001). The procedure evaluated the functional parts of the OEP implementation, that is: (a) facilities; (b) educational material; (c) administration; (d) training; (e) relationships, and ( $f$ ) educational procedures (Grammatikopoulos, Tsigilis, et al., in press). The evaluation of the program's acceptance by the students relied on two indexes: (a) the attitudes of the students toward the OEP and (b) extra-curricular participation of the students.

Educators in the OEP believed that the training would have great impact on their OEP responsibilities (Grammatikopoulos, Papacharisis, et al., 2004). Thus, the evaluation process was considered effective and meaningful. The above results were also verified from the findings concerning the evaluation of program implementation at the end of the school year (self-controlled evaluation) (Grammatikopoulos, Tsigilis, et al., in press). Both internal and external evaluation supported the notion that the training procedure was a necessary ingredient for the success of the implementation of the program (Theodorakis, Goudas, Papacharisis, \& Grammatikopoulos, 2001).

The evaluation results of the OEP implementation revealed the innovative nature of the program and its vital role in the all-day school schedule, the supportive role of the program in spreading the Olympic ideas in Greece as one of its main goals, and many others advantages (Grammatikopoulos, 2004). However, evaluation also revealed that the schools' facilities and equipment did not reach an appropriate quality level in order to support the OEP (Thedorakis et al., 2001).

The above-mentioned conclusions were revealed from both internal and external evaluation. Yet, evaluation could not provide positive conclusion about the role of the school administration in OEP implementation, where the internal and external evaluation provided controversial results (Theodorakis, Goudas, \& Grammatikopoulos, 2002). Internal evaluation supported that school administration did not provide any help in OEP implementation. On the contrary, external evaluation pointed out the vital role of the school principals in OEP implementation.

In order to overcome this problem an additional flexible and self-corrected cvaluation procedure was adopted. The role of the school administration was further studied through interviews with school principals. The qualitative semi-external evaluation (Grammatikopoulos, 2004) revealed that OEP was implemented mostly in extra-curriculum hours, a decision attributed not to the school principals but to the Physical Education Burcau which has the supervision of the program. As a consequence, the principals' evaluation was neither completely internal nor external.

The findings of the above study supported the claims of the internal evaluation. Results indicated a significant percentage $(70 \%)$ of principals who did not contribute to the OEP implementation (Grammatikopoulos et al., in press). This part of the OEP has to be 
further improved, as the role of the school management and principal is of great importance to any educational activity (Dean, 1985; Eliophotou-Menon, 2002; Hall, Mackay, \& Morgan, 1986; Pashiardis \& Orfanou, 1999). The qualitative study also revealed a lack of facilitics and equipment concerning the sport activities of the OEP and not about the cultural and theoretical part of the program: Only 30\% of the principals reported a lack of cquipment provided for theoretical or cultural activities, whereas this percentage exceeded to $50 \%$ for sport activities and to $65 \%$ related to lack of sport fields.

The above finding illustrated a real need concerning the facilities and equipment of OEP program. The quantitative approach could not reveal this very vital point in detail. On the contrary, the qualitative approach permitted the evaluator to study the selected issues in depth and detail (Pation, 1990). It is apparent that in this study the use of an evaluation procedure combining several methods and models revealed findings that otherwise could not have been revealed. Therefore, the vital condition of "selectivity" for dynamic evaluation was met. Regarding the extent to which the goals of the program were achieved, both internal and external evaluation showed that the goals of the OEP were fully met through the activities of the program (Theodorakis et al., 2002).

Students' acceptance of the program was examined through their attitudes toward OEP and the percentage of their participation in extra-curricular hours. The fifty-five Physical Education Bureaus of the country provided the information about students' participation in extra-curricular hours. Data covered one million Greek students with their percentage of participation ( $45 \%$ ) regarded as very satisfactory (Theodorakis et al., 2002). Furthermore, the results of the study examining students' attitudes toward the OEP program indicated that the approximately 3000 students who completed an attitudes questionnaire provided positive feedback (Grammatikopoulos, 2004). In other words, the students considered OEP as a very well accepted program.

\section{Discussion}

The evaluation procedure of this study met the essential conditions for a dynamic approach. First, it was a continuous process functioning as a part of the program. Furthermore, it was flexible as new evaluation activities were easily adopted and selfcontrolled, as the controversial results of internal and external evaluation revealed, and selfcorrected so as to enhance evaluation credibility. The qualitative method used after the disagreement between internal and external evaluation procedures about the role of school administration, is a good example of self-correction enhancing the credibility of the evaluation. Finally, the evaluation procedure was able to provide useful feedback during the implementation of the program (monitoring).

Given the above findings, it can be said that the evaluation conducted in this study managed to ensure the success of the program by giving information (feedback) that could improve the program. For example, evaluation revealed that the schools' facilities and equipment did not reach an appropriate quality level in order to support the OEP. This problem was partially solved by financial support (in the school year 2002-2003) for OEP activities from the Ministry of Education.

The dynamic evaluation of the OEP used various approaches such as: (a) parallel use of internal and external evaluation that is considered meaningful in every educational 
evaluation procedure (Nevo, 2001); (b) goals-results agreement with the evaluation focusing on the extent to which the goals of the procedure were achieved (Tyler, 1949), and (c) the combined use of qualitative and quantitative methods as an ingredient of mixedmethod evaluation designs (Greene \& Caracelli, 1997). Summarizing the above, it can be concluded that "selectivity" was a salient feature of the evaluation process conducted in the current study.

One limitation of the current study - although not by omission of the evaluation design - was that the educators of the OEP were not evaluated. Unfortunately, Greek law relating to educational matters, though currently under consideration, prevents any personnel evaluation procedures.

Dimitropoulos (1999) argued that the dynamic evaluation method could be appropriate for educational evaluation. This study represents the first attempt to apply a dynamic evaluation approach in the field of education. The evaluation process of this study was characterized by the dynamic nature of its adopted procedures.

The findings were encouraging. The results showed the dynamic evaluation method to be a procedure that can be easily carried out in the educational setting. However, many further research attempts are needed in order to ensure that the dynamic evaluation is an efficient evaluation method. As mentioned previously, dynamic evaluation does not adopt any single one of the known evaluation models, so researchers must be very cautious before drawing firm conclusions. Nevertheless, the dynamic evaluation method conducted in this study appeared to be a promising tool concerning the evaluation of educational settings.

\section{References}

Binder, D. (2001). "Olympism" revisited as context for global education: Implications for physical education. Quest, 53, 14-34.

Binder, D. (1994). Bringing the Olympic spirit to life in schools. Paper presented to the 2nd Joint International Session for Directors of National Olympic Academies, and Members and staff Of National Olympic Committees and International Federations, Ancient Olympia, Greece.

Cronbach, L. (1982). Designing evaluations of educational and social programs. San Francisco: Jossey-Bass.

Dean, J. (1985). Manuging the secondary school. Australia: Croom Helm.

Dimitropoulos, E. (1999). Educational evaluation. The evaluation of education and the educational project. Athens: Grigoris.

Eliophotou-Menon, M. (2002). Perceptions of pre-service and in-service teachers regarding the cffectiveness of the elementary school leadership in Cyprus. The International Journal of Educational Mancigement, 16,91-97.

Grammatikopoulos, V. (2004). Evaluation of innovative physical educational programs: Implementation in Olympic education program. Unpublished doctoral dissertation. University of Thessaly, Trikala. 
Grammatikopoulos, V., Tsigilis, N., Koustelios, A., \& Theodorakis, Y. (in press). Developing an instrument to evaluate educational program's implementation. Physical Education and Sport Pedagogy.

Grammatikopoulos, V., Papacharisis, V., Koustelios, A., Tsigilis, N., \& Theodorakis, Y. (2004). Training's evaluation of the Greek Olympic education program. The International Journal of Educational Managenent. 18 (1), 15-24.

Greene, J., \& Caracelli, V. (Eds.) (1997). Advances in mixed-method evaluation: The challenges and benefits of integrating diverse paradigms. New directions for evaluation, 74. San Francisco: Jossey Bass.

Guskey, R.T. (2000). Evaluating professional development. Thousand Oaks, CA.: Corwin Press.

Hall, V., Mackay, H., \& Morgan, C. (1986). Headteachers at work. Milton Keynes: Open University Press.

Kioumourtzoglou, E., Theodorakis, I., Avgerinos, A., Kellis, I., Papacharisis, V., Hasandra, M. (2001). Olympic education: From theory to praxis. Athens: Livani.

Naul, R. (1998). Olympic ideals and Olympic education of youth. In R. Naul, K. Hardman, M. Pieron, \& B. Skirstad (Eds.), Physical activity and active lifestyle of children and youth (pp. 29-48). Schorndorf: Karl Hofmann.

Nevo, D. (2001). School evaluation: Internal or external. Studies in Educational Evaluation, 27, $95-$ 106.

Pashiardis, P., \& Orfanou, S. (1999). Insight into elementary principalship in Cyprus: The teachers' perspective. The International Journal of Educational Management, 13, 241-251.

Patton, M.Q. (1990). Qualitative evaluation and research methods. London: Sage.

Pekelis, V. (1986) Cybernetics. Athens: Gutenberg.

Theodorakis, Y., Goudas, M., Papacharisis, V., \& Grammatikopoulos, V. (2001). Evaluation report of the Olympic education program. January-June 2001. Trikala: University of Thessaly.

Theodorakis, Y., Goudas, M., \& Grammatikopoulos, V. (2002). Evaluation report of the Olympic cducation program. Fall 2001 - June 2002. University of Thessaly: Trikala. Chicago.

Tyler, R.W. (1949). Basic principles of curriculum and instructions. Chicago: University of

Worthen, B.R., \& Sanders, J.R. (1987). Educational evaluation. Alternative approaches and practical guidelines. New York: Longman.

Note

1. This study was funded by a research grant from the Greek Ministry of Education through the Research Committee of the University of Thessaly (Code 2968). 
The Authors

VASILIOS GRAMMATIKOPOULOS is teaching in the Department of Physical Education and Sports Science at the University of Thessaly, Greece. He is a member of the American Evaluation Association and of the Hellenic Academy of Physical Education. He has a B.Ed. in physical education and sport science, an M.Sc. in school physical education and a Ph.D. in educational evaluation.

ATHANASIOS KOUSTELIOS is an associate professor in the Department of Physical Education and Sports Science at University of Thessaly, Greece. He was elected President of the Greek Association of Sport Management (2002-2004). He has a B.Ed. in physical education and sport science and Ph.D. in human recourse management.

NIKOLAOS TSIGILIS is teaching in the Department of Physical Education and Sports Science at University of Thessaly, Greece. He has a B.Ed. in physical education and sport science, an M.Sc. in school physical education and is a Ph.D. candidate in research methods.

YANNIS THEODORAKIS is professor of Sport Psychology in the Department of Physical Education and Sport Science at the University of Thessaly, Greece and Head of the Department. He was elected member in Managing Council of European Society of Sport Psychology (1999-2003). He is Member of the Editorial Board of Psychology of Sport and Exercise. He has a B.Ed. in physical education and sport science and Ph.D. in Sport and Excrcise Psychology.

Correspondence: <gravas(@) pe.uth.gr> 